\title{
$\underline{\text { A Case Report }}$
Transcatheter Closure of Patent Ductus Arteriosus with Pulmonary Arterial Hypertension of Down Syndrome Children: Case Reports:

\author{
Corresponding author: Tahera Nazrin*
}

${ }^{*}$ Consultant, Clinical and Interventional Pediatric Cardiologist, Evercare Hospital Dhaka, Bangladesh.

Received on: 12-10-2020; Revised and Accepted on: 23-10-2020

\begin{abstract}
Patent ductus arteriosus is common congenital heart disease in Down syndrome children. Patent ductus arteriosus (PDA) can cause repeated pneumonia, pulmonary hypertension, congestive cardiac failure, and an increased risk for endocarditis. Transcatheter closure of PDA is preferential therapeutic alternative to surgical ligation. Two Down syndrome babies associated with PDA with pulmonary arterial hypertension are described with the history of failure to thrive, developmental delay, and recurrent hospital admission for LRTI. We closed their PDA with Amplatzer PDA device successfully. One baby had additional mild right pulmonary artery (RPA) stenosis and atrial ectopic which disappeared within 6 months of the procedure. His frequency of LRTI gradually decreased and growth pattern also improved. Another baby had moderate sized PDA with moderate pulmonary hypertension with almost same type of history. Additionally, she had history of heart failure with pneumonia for two times. But she had good flow in branch pulmonary arteries and normal heartbeat. She improved clinically and hemodynamically after 6 months after the procedure. We could help both the parents in time to get rid of anxiety with their Down syndrome children for their cardiac and respiratory problems. Infact a Down syndrome baby needs a good social support for maintenance of their life at least near to normal.
\end{abstract}

Keywords: Patent Ductus Arteriosus, Pulmonary arterial hypertension, Down syndrome, Amplatzer PDA device closure.

\section{INTRODUCTION:}

The incidence of Patent ductus arteriosus in full term infant is about $5 \%-10 \%$ of all types of congenital heart diseases. ${ }^{1}$ The pulmonary orifice of the ductus is located immediately to the left of the bifurcation of the pulmonary trunk near the origin of its left branch and aortic orifice is located immediately distal to the origin of the left subclavian artery .2 The reported prevalence of down syndrome with PDA has wide variation. Different studies in different countries show a good association of PDA with Down syndrome .3,4,

Down syndrome baby's lung function is compromised if there is PDA which actually continuously drains blood from high pressure aorta to low pressure lungs. Also, Down Syndrome

\footnotetext{
*Corresponding author:

Tahera Nazrin

Consultant, Clinical and Interventional Pediatric Cardiologist, Evercare Hospital Dhaka, Bangladesh.

DOI: $10.46978 /$ sjc.20.1.2.17
}

children with PDA are more prone to develop high pulmonary pressure early. Patent ductus arteriosus (PDA) can cause repeated pneumonia, pulmonary hypertension, congestive cardiac failure and an increased risk for endocarditis. ${ }^{5}$

But clinical course of Down syndrome and outcome of medical and surgical treatment are more favorable when the condition is detected early and pulmonary hypertension, a frequent complication can be avoided. 6-7 Transcatheter closure of PDA is currently the preferred therapeutic alternative to surgical ligation. 5

\section{Case History 1:}

A 1.5-year-old boy of Down syndrome weighing $9.5 \mathrm{~kg}$ incidentally was diagnosed as a case of PDA by a Pediatrician and was referred to Paediatric Cardiologist for further management. The baby had a history of repeated lower respiratory tract infection (LRTI), failure to thrive and developmental delay since last one year and half year. He also had a history of repeated hospital admission for that purpose in remote area where he resided. He had been on treatment as a case of LRTI. On examination, baby had mild dyspnoea, mild pallor and delayed milestone of development. His heart rate: 
125 /m, R.R: 26/m, B.P: 95/35mmHg, SP02 99\% in room air. His precordium was hyperdynamic apical impulse was at $5^{\text {th }}$ left ICS lateral to MCL. His $1^{\text {st }}$ and $2^{\text {nd }}$ heart sounds were fainty heard because of intense continuous machinery murmur 4/6 all over the precordium best heard on left $2^{\text {nd }}$ intercostal space. Lungs were clear. His chest x-ray showed cardiomegaly with plethoric lung fields. ECG showed sinus nodal dysfunction with atrial ectopic with nodal rhythm. Echo revealed moderate sized PDA (ampulla : $6 \mathrm{~mm}$, pulmonary end : $4 \mathrm{~mm}$ ), L-R (left to right ) shunt, PDA gradient : 40/15 mmHg ( Table 1).He had also mild right pulmonary artery (RPA) stenosis with flow gradient (16mm Hg ) with LA ( left atrium ), LV ( left ventricle) dilation and mild pulmonary hypertension. All laboratory investigations were within normal range. So, Paediatric Cardiologist decided to close the PDA by Amplatzer device immediately.

\section{Case history 2:}

A 2-year-old girl weighing $11 \mathrm{~kg}$ diagnosed as a case of Down syndrome with PDA by a Neonatologist since birth and she was on occasional follow up. She was brought to Paediatric Cardiologist for device closure of PDA. The baby had history of feeding problem, repeated lower respiratory tract infection (LRTI), failure to thrive and developmental delay. She had history of hospital admission for recurrent LRTI and for heart failure with aspiration pneumonia for two times. On examination, baby was dyspnoeic, mildly pale, and with mild developmental delay.

Her parents were very anxious about her. Clinically the baby was febrile, dyspnoeic and anxious with hyper dynamic chest and mild chest in drawing. Her heart rate: 155 /m, R.R: 45/m, B.P:105/40 mmHg and SPO2 96\% in room air. Her apical impulse was thrusting, and heart sound were masked by loud and harsh continuous machinery murmur 5/6 all over the precordium best heard on left $2^{\text {nd }}$ intercostal space with radiation to back. Breath sound and added sound of lungs could not be elicited properly. He had mild hepatomegaly. His x-ray chest showed cardiomegaly with plethoric lung fields and patchy opacity. ECG denoted normal sinus rhythm, wide $\mathrm{P}$ wave, deep $\mathrm{Q}$ and tall $\mathrm{R}$ wave in leads II, III aVF and the left precordial leads V5 and V6. Echo revealed moderate sized conical shaped PDA (ampulla: $8 \mathrm{~mm}$, pulmonary end: $6 \mathrm{~mm}$ ) LR shunt, PDA gradient: 41/10 mmHg (Table 1). He had dilated LA, LV with moderate pulmonary hypertension. Hematological investigations showed low $\mathrm{Hb}(10 \mathrm{gm} / \mathrm{dl})$ with neutrophilic leucocytosis. We treated the baby as Pneumonia with impending heart failure. After her recovery Paediatric Cardiologist decided to close the PDA by Amplatzer PDA device immediately.

\section{PROCEDURE}

Case 1:

Baby was intubated during procedure. The baby was draped properly. We used $4 \mathrm{~F}$ (French) groin sheath for right femoral artery and 5F groin sheath for right femoral vein. On lateral projection (lateral 900 view) an aortogram was done by $4 \mathrm{~F}$ Pigtail to confirm the size and site of PDA which confirmed the conical shaped PDA with similar to the sizes (ampulla $6 \mathrm{~mm} /$ pulmonary end $4 \mathrm{~mm}$ ) of echo report. By $5 \mathrm{~F}$ multipurpose catheter pulmonary arterial pressure measured which was 55/20 mmHg. Hand injection to pulmonary arteries showed unobstructed antegrade flow and good levophase which excluded any significant stenosis of pulmonary arteries. Amplatzer J-tip stiff wire was introduced through PDA to aorta. Over the guide wire 6F Amplatzer delivery sheath was introduced up to descending aorta and wire was removed. Baby developed bradycardia, irregular heartbeat with prolonged PR interval for few minutes while the sheath was crossing the PDA into descending aorta. But he recovered spontaneously. Then the delivery cable was passed through the loader. The suitable PDA Amplatzer device ( $8 \mathrm{~mm} \times 6 \mathrm{~mm}$ ) was immersed in saline and put on the tip of the delivery cable and screwed in clockwise direction. Then the device was pulled into the loader under water seal to minimize air trapping. The delivery cable with device on the tip was introduced through the delivery sheath and forwarded without any rotation into the descending aorta. Only the retention disc of the device was first deployed by peeling of delivery sheath over it. Then the whole device delivery sheath assembly was pulled back into the ampulla until the tugging sensation of aortic pulsation. After that the cylindrical portion was implanted thereby plugging the PDA. Repeat aortogram demonstrated the device in good position without any residual leak and no protrusion into the LPA. Device was deployed by unscrewing ante clockwise. Post device closure pulmonary pressure came down $40 \mathrm{mmHg}$.Then the catheter and other sheaths were removed with proper haemostasis. After the procedure, the baby was kept in ICU on NPO for 5 hours, I.V fluid, I.V antibiotic and one dose inj. lasix. Check echo confirmed PDA device in situ without any obstruction of LPA and aorta. Mild RPA stenosis was matter of concern for us. Baby was discharged on next day with low dose diuretic and advice for follow up after 7 days.

\section{Case 2:}

Procedure was same as other one. Baby did not develop any complications during procedure. We used $5 \mathrm{~F}$ arterial and 5Fvenous groin sheath, $5 \mathrm{~F}$ pigtail, $5 \mathrm{~F}$ multipurpose and $7 \mathrm{~F}$ Amplatzer delivery sheath. His pulmonary arterial pressure (systole/diastole) was 64/30 mmHg which decreased after 10 minutes of device closure to 40/25 mm Hg. Aortogram showed the exact size (ampulla: $8 \mathrm{~mm}$, pulmonary end $6 \mathrm{~mm}$ ) and conical shape of PDA (Fig:1). We put 10/8 Amplatzer PDA occluder for her (Fig: 2). 
TABLE: 1

\begin{tabular}{|c|c|c|}
\hline Study parameters & Case 1 & Case 2 \\
\hline Size of PDA (mm) & $6 / 4$ & $8 / 6$ \\
\hline PDA gradient (Systolic/Diastolic mmHg) & $40 / 15$ & $41 / 10$ \\
\hline Pulmonary pressure(mmHg) & $55 / 20$ & $64 / 30$ \\
\hline Size of Amplatzer PDA device (mm) & $8 / 6$ & $10 / 8$ \\
\hline
\end{tabular}

\section{FOLLOW UP}

Case 1: On $7^{\text {th }}$ day and one month of follow up the baby was fine with normal haemodynamics. ECG showed the same as before procedure. Echo revealed PDA device in situ with mild dilation of left atrium (LA) and left ventricle (LV) with mild RPA stenosis. On third month of follow up his ECG was normal. Color Doppler echocardiography showed that LA, LV normal without any pulmonary arterial hypertension except mild RPA stenosis. His oral diuretic was stopped. On $6^{\text {th }}$ month of follow up we found on echo that normal flow of RPA and unobstructed blood flow through LPA and aorta. His growth and development improved dramatically. He had no history of LRTI within one year of follow up.

Case 2: After 7 days of procedure clinically she was improving. Her echo revealed device in situ with dilated LA, LV, and mild pulmonary arterial hypertension. We kept the baby on diuretics and ACE inhibitor for one month. But after one month and thereafter three months follow up, we could not stop the oral medicine as her LA, LV was still dilated with pulmonary hypertension. On $6^{\text {th }}$ month of follow up we found normal cardiac dimensions with no pulmonary hypertension. On one year follow up we observed the notable improvement of her growth and development. She had only two episodes of cough and cold which was relieved by oral medications but no history of hospital admission after device closure.

\section{DISCUSSION}

Down Syndrome (DS) was first described in 1866 by John Langdon Down. The prevalence of congenital heart disease (CHD) in DS is common ${ }^{3,4}$ approximately $43 \% .^{8}$ Among CHD, preponderance of PDA is significant in DS. ${ }^{8}$ Patent ductus arteriosus (PDA) is one of the extra- cardiac shunt that can lead to pulmonary hypertension due to volume overload of pulmonary circulation and to structural remodeling of pulmonary vasculature. 8

It is reported that PDA affect both heart and lungs. Down Syndrome with PDA are prone to develop repeated LRTI, pulmonary arterial hypertension and heart failure more frequently. Therefore, PDA should be closed in time. ${ }^{5}$ It is important to be familiar with the incidence and anatomic characteristics of congenital heart disease in Down syndrome, as well as associated minor and major complications and causes of morbidity and mortality. So that we can apply preventive measures and improve their quality of life. ${ }^{9}$
Jesus de Rubens Fingueroaa, Blance del Pozzo Magna et al in their study in National Institute of Paediatrics in Mexico City demonstrated that among 275 children 160 (58\%) presented different types of congenital heart diseases. Among them most frequent were PDA, combining both isolated PDA (33) and associated with other cases were present in 67 cases. They also showed clinical course of PDA with Down syndrome and outcome of medical and surgical treatment are more favorable when the condition is detected early and pulmonary hypertension, a frequent complication can be avoided.$^{10}$

Khositseth A 1 and Wanitkun S stated in their study "Patent ductus arteriosus associated with pulmonary hypertension and desaturation" that the cases of three children with patent ductus arteriosus (PDA), pulmonary hypertension (PAH) and desaturation. The two children of them were Down syndrome with PDA with desaturation. One had desaturation only at room air oxygen (21\% oxygen) but well saturated with $100 \%$ oxygen, subsequently underwent successful device closure of the PDA with improvement.11 PDA can be closed by transcatheter device closure or by surgery. In comparison to surgery transcatheter closure is mostly preferred by parents because of avoiding bypass, short hospital stay and PDA closure without any scar mark. Hence device closure is the first choice for PDA treatment in many centers except very tiny \& very large, bizarre PDA, which are sent for surgical closure. ${ }^{12,13,14,15}$

The first attempt at transcatheter closure of PDA was made in 1967 by Portsman et al using an Ivalon plug. Thereafter, several devices were introduced, but most had high embolization or residual shunt rates and were withdrawn from use. 16,17 The devices currently in use include Gianturco coils, Gianturco-Grifka vascular occlusion devices, the Duct occlude PFM coil, the detachable Cook's coil and Amplatzer duct occluder. ${ }^{18}$ The Amplatzer duct occluder has emerged as a very successful, less invasive alternative to surgery to close moderate to large ducts. ${ }^{5}$

There are very less complications are seen during PDA device closure. But we should be very careful about the occasional ductal spasm during aortography which can lead to significant under sizing and device embolization ${ }^{5}$ This, however, did not happen in our patients.

Hemolysis due to intra device or residual leakage has been reported with both coils and ADO (Amplatzer duct occluder). ${ }^{19}$ In our patient hemolysis was not seen. 
Device embolization occurred in 5 years old girl with $11 \mathrm{~mm}$ PDA which was closed by Amplatzer muscular VSD device in a study group of Mehnaj Atiq et al. ${ }^{5}$

We observed the device in situ of our patients by color doppler echocardiography just after procedure and on subsequent follow up.

In India, Shrivastava and colleagues reported a series of PDA device closure with spring coils \& Amplatzer duct occluder. They had the experiences of $100 \%$ closure of PDA at the end of 3 months. ${ }^{13}$

In our patients, immediate occlusion of PDA occurred without any residual leak.

Khaleel et al described that there is high incidence of pulmonary arterial hypertension among Down syndrome children with CHD compared to non-Down syndrome (NDS) children. They described in their study that pulmonary arterial hypertension was significantly higher among DS children with high prevalence of PDA. It was described that Patent ductus arteriosus (PDA) and age of $>6$ months were the main risk factors for the development of PAH among DS children. ${ }^{20}$

We also observed that our baby's pulmonary hypertension reduced to normal level by one to three months of follow up.

2D and color doppler echocardiography findings guided us to measure pre and post procedure pulmonary arterial hypertension. Reduced frequency of LRTI and improving growth of these children were also keen fully noted.

Douglas Bush et al showed in their retrospective study that pulmonary hypertension is familiar in children with Down syndrome, is typically transient and moreover is related to congenital heart disease like PDA and PPHN but can recur if they have association with respiratory diseases such as obstructive sleep apnea, intermittent hypoxia, and recurrent pneumonia. ${ }^{21}$

Our children had pulmonary hypertension typical transient type. Post procedures follow up their pulmonary hypertension did not recur which was regularly evaluated by echocardiography.

\section{CONCLUSION}

Down syndrome children with PDA are more prone to develop grave signs and symptoms of cardiovascular and respiratory system which may endanger their lives.

Early detection and closure of PDA with Down syndrome children can decrease their morbidity and mortality and improve the quality of life in no doubt.

\section{ACKNOWLEDGEMENT}

\section{Dr. Mahmoud Al Soufi}

Consultant

Clinical and Interventional Paediatric Cardiology

Al Jalila Children Specialty Hospital, Dubai.

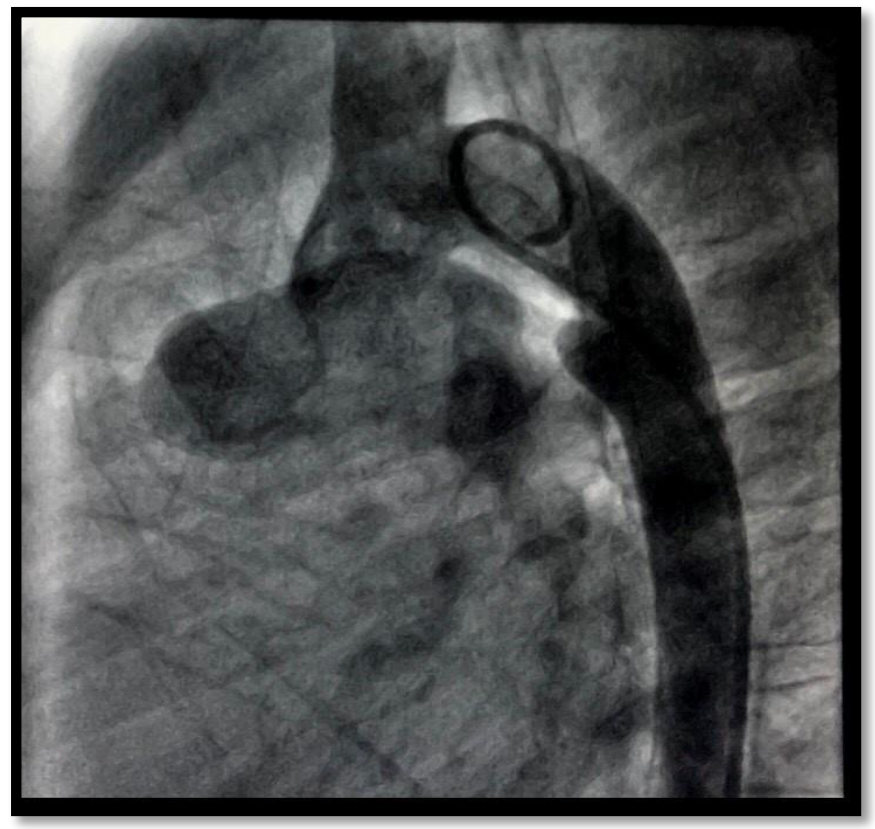

Fig 1: Aortogram showing PDA.

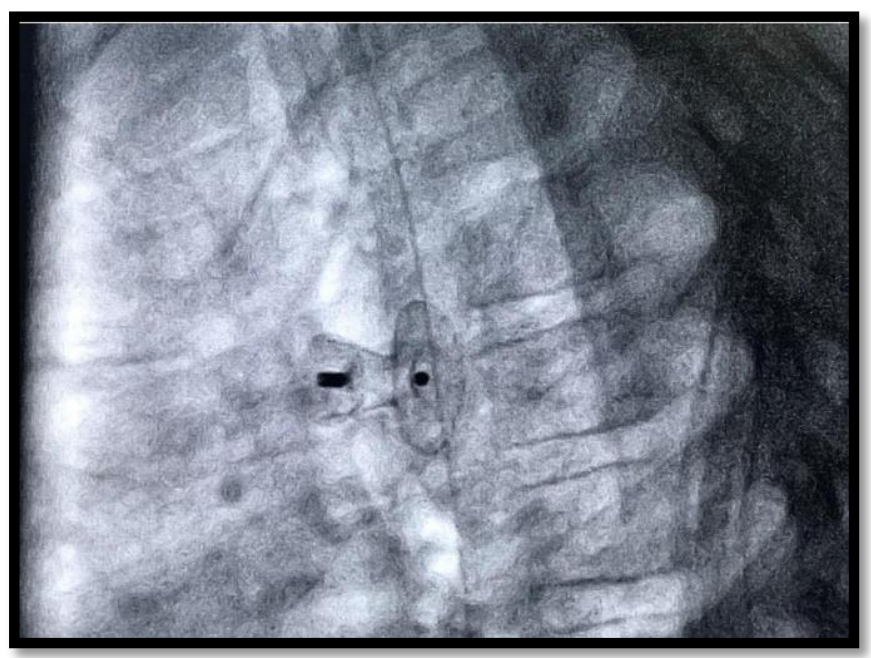

Fig 2: Deployment of Amplatzer PDA Device.

\section{REFERENCES}

1. Nathaniel W. Taggart, Mohammed Yasir Qureshi. Patent Ductus Arteriosus and Aortopulmonary Window. Moss and Adams' Heart Disease in infants, children, and adolescents 
including fetus and young adults, 2016; Vol II,9th edition:31: 803.

2. Joseph K, Perloff, Ariane J, Marelli. Patent Ductus Arteriosus Aortopulmonary Window. Perloff's Clinical recognition of congenital heart disease. Elsevier. 2012. 6th edition:20: 368.

3. Freeman SB, Taft LF, Dooley KJ, Allran K, Sherman SL, Hassold TJ, et al. Population based study of congenital heart defects in Down syndrome. Am J Med Genet 1998: 80: 213-7.

4. Stoll C, Alembik Y, Dott B, Roth MP. Study of Down Syndrome in 238, 942 consecutive births. Ann Genet 1998: 44-51.

5. Mehnaj Atiq, Nadeem Aslam, Khawar A Kazmi. Transcatheter closure of small to Large Patent Ductus Arteriosus with different Devices: Queries and Challenges , JIC, Vol 19-issue 7 July 2007.

6. Rizzoli G, Mazzucco A, Maizza F, Daliento L et al. Does Down syndrome affect prognosis of surgically managed atrioventricular canal defect? J Thoracic and Cardiovascular surgery 1992; 104: 945-53.

7. Baciewicz FA, Melvin WS, Bssilius D Congenital heart disease in Down Syndrome patients: a decade of surgical experience. Thoracic and Cardiovascular surgery 1989, 37: 369- 71.

8. Nilda Espinola- Zavaleta, María Elena Soto, Angel RomeroGonzalez, Lidia del Carmen Gómez-Puente, Luis MuñozCastellanos, Aasha S. Gopal, Candace Keirns, Eulo LupiHerrera, Prevalence of Congenital Heart Disease and Pulmonary Hypertension in Down's Syndrome: An Echocardiographic Study. J Cardiovasc Ultrasound. 2015 Jun; 23(2): 72-77. Published online 2015 Jun 26.

9. Benhaourech, Sanaa, Drighil, Abdenasser, El Hammiri Ayoub. Congenital heart disease and Down syndrome: various aspects of a confirmed association. Cardiovasc J Afr. 2016 Sep- Oct; 27(5): 287-290.doi: 10.5830/CVJA-2016-019.

10. Jesús de Rubens Figueroa, Blanca del Pozzo Magaña, José L Pablos Hach, Claudia Calderón Jiménez, Rocío Castrejón Urbina. Heart Malformations in Children with Down Syndrome.Rev Esp Cardiol. 2003;56(9):894-9.

11. Khositseth A 1 and Wanitkun S "Patent ductus arteriosus associated with pulmonary hypertension and desaturation" Cardiol J .2012; 19(5): 543-6.

12. Faella H J, Hijazi ZM, et al. Closure of the Patent ductus arteriosus with the amplatzer PDA device: Immediate result of the International clinical trial. Catheter Cardiovasc Intervn (2000 Sep); 51(1): 50-54.

13. Shrivastava S, Mahawar A, Radhakrishnan S. Transcatheter closure PDA, Indian Paediatrics, 2000; 37: 1307-1313.
14. Marwah A, Radhakrishnan S, Shrivastava S. Immediate and early result of closure of moderate to large patent ductus arteriosus using the new Amplatzer devices. Cardiol Young 2000: 10: 208.

15. Thanopoulous BD, Hakim FA, Hiari A, Gaussous Y, further experience with Transcatheter closure of ductus arteriosus using the amplatzer duct occluder. J Am coll cardiol 2000; 35 : 1016-21.

16. Porstmann W, Wierny L, Warnke H, et al. Catheter closure of patent ductus arteriosus: 62 cases treated without thoracotomy. Radiol Clin North Am 1991:9:203-218.

17. Wierny L, Plass R, Porstmann W. Transluminal closure of patent ductus arteriosus: Long- term results of 208 cases treated without thoracotomy. Cardiovasc Interv Radiol 1986:9:279-285

18. Moore JW, Levi DS, Moore SD, et al. Interventional treatment of patent ductus arteriosus in 2004. Catheter Cardiovasc Interv 2005 ;64:91-101.

19. Ujun O, Dickinson D, Parsons Jet al. Residual and recurrent shunts after implantation of Cook detachable dual occlusion coils. Heart 1998; 79: 220-222.

20. Khaleel Ibrahim, ALSUWAYFEE, Mohammed et al. Congenital heart disease and pulmonary hypertension among Down syndrome pediatric patients. Annals of the College of Medicine, Mosul, 2020, Volume 42, Issue 1, Pages 50-56 10.33899/mmed.2020.126534.1017.

21. Douglas Bush , Csaba Galambos , D Dunbar Ivy , Steven H Abman, Kristine Wolter- Warmerdam, Francis Hickey. Clinical Characteristics and Risk Factors for Developing Pulmonary Hypertension in Children with Down Syndrome. J Pediatr: 2018 Nov; 202:212- 219. e2.doi: 10.1016/j.jpeds.2018.06.031. Epub 2018 Jul 17. 


\section{Article Citation:}

Authors Name. Tahera Nazrin. Transcatheter Closure of Patent Ductus Arteriosus with Pulmonary Arterial Hypertension of Down Syndrome Children: A Case Report. SJC 2020;1(3): 107 - 112

DOI: $10.46978 /$ sjc.20.1.2.17 